\title{
What Happens When Business Schools Merge: A Case Study
}

Pascal Nguyen, Ph.D., NEOMA Business School, France

\begin{abstract}
Following in the steps of for-profit companies, business schools have started to consider mergers as a way of rapidly boosting their visibility and financial resources. However, there are challenges to address. This case describes the recent experience of two major French business schools. The focus is on the changes made to faculty management. The case offers an opportunity to reflect on the benefits and potential pitfalls of the new workload policy.
\end{abstract}

Keywords: Business Schools; Mergers; Faculty Management; Workload Policy

\section{INTRODUCTION}

n the spring of 2013, Rouen Business School and Reims Management School, two major French business schools located near Paris, announced their merger to become NEOMA Business School.

While comparable in size and reputation among students and employers alike, the two schools had distinct cultures and procedures with regard to faculty management. Among the most pressing issues was the need to define common rules. This case presents some of the most visible measures affecting the faculty. It offers the opportunity to reflect on their potential benefits and consider their likely consequences. In addition, the background material can be used to evaluate the benefits of a merger between two business schools. Suggested questions and possible answers are provided at the end of the case.

\section{BACKGROUND INFORMATION}

NEOMA Business School is a French business school. Its 9,000 students, including 2,000 international students, are enrolled in various programs, whose quality is recognized by the coveted AACSB, AMBA, and EQUIS accreditations. The faculty is made up of 200 professors (including foreign language instructors) assigned to 7 academic departments. The school's budget, at about $€ 75$ million, is one of the biggest in France.

The school's mission statement is to educate future entrepreneurs and managers in responsible leadership with the ability to go beyond prevailing models. In line with other French business schools, training involves a significant study period overseas. Students complement their local education by taking part in exchange programs with some of the world's finest institutions (Emory, Indiana, Queen's, Tel Aviv, Tsinghua, HKUST, Seoul National University). Professional experience in the form of a semester-long internship is also one of the school's core educational principles. In addition, a significant proportion of students benefit from an apprenticeship scheme that combines professional work with study time under the close supervision of a faculty member.

The flagship graduate program is the Master in Management, in which more than half of the students are enrolled. Admission is normally through a competitive entrance examination that requires two years' intensive preparation after high school. Parallel admissions are also possible for candidates with the suitable profile. In addition, a number of undergraduate programs are proposed, each with a distinctive focus. For instance, the Bachelor in International Business emphasizes international trade and the acquisition of several foreign languages. Likewise, the Bachelor in Technology and Management aims to produce managers and entrepreneurs capable of leading innovative projects. 
At graduate level, NEOMA Business School also offers master's degrees in finance, marketing, supply chain management, and global business. The aim of these programs is to meet demand in underserved markets by providing students with highly specialized skills. Intake in each program is limited to a few dozen students who can follow electives from the Master in Management program in addition to their own courses.

\section{HISTORY OF THE MERGER}

NEOMA Business School was born in 2013 out of the merger of two well-respected French business schools: Rouen Business School and Reims Management School. Rouen Business School was one of the oldest business schools in France. Founded in 1871, managed and financed by the local chamber of commerce, its primary role was to train business leaders to support French interests in overseas postings. Reims Management School had similar characteristics. Both schools have always enjoyed a strong reputation in France and have received praise for their highly employable graduates. The Financial Times ranked their Master in Management programs among the best in Europe $\left(13^{\text {th }}\right.$ for Rouen and $22^{\text {nd }}$ for Reims). Each school had been awarded the triple AACSB, AMBA, EQUIS accreditation.

The motives behind the merger lay in the recognition of increasing competition for local and international students. In order to make their programs more attractive and increase their visibility, French business schools had to grow in size and secure greater financial resources. Only HEC Paris has a worldwide reputation and can attract the best international students. It supports its position as leader with a resolute commitment to top-quality research. Table 1 shows the top 20 French business schools with their research output for the year 2012. The figures for NEOMA are based on those for Reims and Rouen. Each publication is awarded a number of stars according to the journal's ranking in the CNRS list. The most selective journals confer 4 stars while uncategorized journals confer none. Looking at the average number of stars per article in the last column points to the strategy followed by each school. For instance, ESC Rennes has achieved roughly the same number of stars as EM Strasbourg, but with fewer papers that are on average of higher quality.

Schools without the appropriate scale could grow organically by increasing student intake in their existing programs and creating new degrees. However, merging was seen by many as a quick way to boost their resources and assert their global ambitions. Among the numerous benefits accruing from a merger, the advertising budget could increase significantly in absolute terms, yet become a smaller proportion of total costs. The schools could also leverage their respective competences and develop new synergies. The faculty in Rouen had strength in finance and logistics; Reims was strong in marketing and had developed close ties with the champagne industry. The combined entity could contemplate launching a $\mathrm{PhD}$ program, to which each school had long aspired. It would also stand a better chance of winning corporate clients by offering customized training programs drawing on the strengths of a larger faculty.

Furthermore, Rouen Business School and Reims Management School were both threatened by dwindling funding from the local chambers of commerce on which they had traditionally relied to balance their books. Meanwhile, the chambers of commerce were eager to put the schools on stronger financial footing. Given that they held the overwhelming majority of board seats of each school, the decision to proceed with a merger could be quickly achieved.

In the face of increasing financial pressure, several other schools had already merged. Skema Business School is the result of the merger between two medium-sized schools, one based in Lille and the other in Nice. Kedge Business School is the result of schools in Bordeaux and Marseille tying the knot. A decade earlier, Parisbased ESCP had absorbed the lower-ranked EAP raising alarm among its alumni. Nonetheless, the merger gave ESCP a strong European foothold. EDHEC had shown that managing a faculty across distant campuses was not impossible. In fact, it is successfully challenging the best European schools thanks to its unique focus on finance and risk management. In contrast, France Business School, which attempted to combine four smaller-sized institutions, recently collapsed. 
Table 1. Major French business schools and research output for 2012

\begin{tabular}{|c|c|c|c|c|c|}
\hline School name & Stars & Articles & Faculty & Stars / Faculty & Stars / Article \\
\hline 1. HEC; Jouy-en-Josas & 169 & 53 & 126 & 1.34 & 3.2 \\
\hline 2. Kedge; Bordeaux, Marseille & 126 & 64 & 166 & 0.76 & 2.0 \\
\hline 3. EDHEC; Lille, Nice, Paris & 125 & 53 & 86 & 1.45 & 2.4 \\
\hline 4. ESSEC; Cergy-Pontoise & 102 & 38 & 102 & 1.00 & 2.7 \\
\hline 5. IESEG & 93 & 35 & 71 & 1.31 & 2.7 \\
\hline 6. ESC Grenoble & 91 & 41 & 89 & 1.02 & 2.2 \\
\hline 7. ESCP Europe; Paris & 90 & 40 & 105 & 0.86 & 2.3 \\
\hline 8. EM Lyon & 85 & 36 & 103 & 0.83 & 2.4 \\
\hline 9. Audencia; Nantes & 78 & 42 & 73 & 1.07 & 1.9 \\
\hline 10. Skema; Lille, Nice, Paris & 71 & 35 & 117 & 0.61 & 2.0 \\
\hline 11. NEOMA; Reims, Rouen & 70 & 39 & 141 & 0.50 & 1.8 \\
\hline 12. EM Strasbourg & 49 & 29 & 55 & 0.89 & 1.7 \\
\hline 13. ESC Rennes & 48 & 22 & 48 & 1.00 & 2.2 \\
\hline 13. IPAG Business School & 48 & 24 & 47 & 1.02 & 2.0 \\
\hline 15. ESC Toulouse & 44 & 21 & 69 & 0.64 & 2.1 \\
\hline 16. ISC Paris & 37 & 16 & 69 & 0.54 & 2.3 \\
\hline 17. ESC Dijon & 36 & 22 & 52 & 0.69 & 1.6 \\
\hline 18. ESC Montpellier & 35 & 22 & 51 & 0.69 & 1.6 \\
\hline 19. France Business School & 29 & 20 & 145 & 0.20 & 1.5 \\
\hline 20. ESG Management School & 28 & 18 & 54 & 0.52 & 1.6 \\
\hline
\end{tabular}

Source: L'Etudiant (http://www.letudiant.fr/educpros/enquetes/ecoles-de-commerce-le-palmares-2014-de-la-recherche-engestion.html).

\section{Changes in Faculty Management}

While mergers may present some attractive features, combining two different organizations can be challenging. Here, the schools had different administrative procedures and standards for their faculties. Rouen Business School had formally classified its faculty into assistant, associate and full professors. Expectations in terms of research, teaching and service were clearly spelled out. Promotion to a higher rank followed an open and transparent procedure. In addition, financial incentives and teaching relief were provided to encourage faculty members to publish in high-quality journals. This policy also helped attract promising young academics, as well as more experienced staff, from well-regarded institutions. In comparison, Reims Management School did not rank its faculty members formally. Accordingly, there was no need to set up specific standards. Publication was tacitly encouraged without being explicitly rewarded. Unsurprisingly, many in the faculty chose to devote their time to consulting activities while others chose to do more off-load teaching which was relatively well paid.

One of the main tasks for the newly-formed school was thus to devise common standards for the entire faculty. Besides, greater accountability needed to be introduced in faculty management. Drawing on the experience of each school, a number of principles were developed and set out in a revised faculty handbook.

The faculty is now divided in two groups: academically qualified (AQ) and professionally qualified (PQ). For faculty members in the AQ group, the requirement is to publish the equivalent of 3 stars over a three-year period. This objective might seem to be straightforward, but it is almost impossible to achieve for faculty members who have never published or have not done so in recent years. Teaching load for AQ staff is set at 180 hours a year. Teaching relief is no longer offered for the simple reason that AQ staff are expected to publish. Accordingly, there is no need to offer further publication incentives. For faculty members in the PQ group, the teaching load is much heavier, and varies from 270 hours for a clinical professor to 450 hours for a senior lecture on a full teaching load. On the other hand, there is no requirement to publish in peer-reviewed journals. Each faculty member is required to choose a group and stick to it for the next three years. At that point, their performance will be appraised and they could receive cautions.

Based on the principle that faculty members need to keep their teaching up-to-date at all times, all courses are now equally weighted. Previously, courses received a weighting of 1.5 when they were taught for the first time. To encourage the faculty to teach in English, which might involve greater effort and preparation for French 
speakers, courses delivered in English could receive an additional weighting of 1.5. Hence, a new 36-hour course taught in English could count as much as an 81-hour existing course taught in French. However, with the increasingly diverse faculty profile, the use of English as language of instruction is now well-established and may no longer require a higher weighting.

\section{AUTHOR INFORMATION}

Pascal Nguyen is Associate Professor at NEOMA Business School. He received his PhD in Management Science from ESSEC Business School. His research interests include corporate governance and risk management. His work has appeared in Corporate Governance: an International Review, Journal of Risk and Insurance, Geneva Risk and Insurance Review, Journal of Economic Dynamics and Control, Journal of the Japanese and International Economies. He was previously affiliated with the University of New South Wales and the University of Technology Sydney where he was the director of the Honours program in finance. 


\section{DISCUSSION QUESTIONS}

The subject matter in this case study is relevant to undergraduate and graduate-level courses in Business Economics, Human Resource Management, Leadership, and Organizational Behavior. The following questions can serve as a catalyst for more in-depth class discussion.

1. Present the rationale for the merger between the two schools.

2. Present the arguments for revisiting the teaching loads.

3. Describe the most likely choice for non-research-active staff.

4. Describe the likely effect on teaching quality.

5. What might be the unintended consequence of removing the higher weighting for new courses?

\section{Suggested Answers}

\section{Rationale for merging the two schools}

As in the case of corporate mergers, combining two schools can bring a variety of benefits.

\section{Positive synergies:}

The merger can help bring out the best in each school. In this instance, Rouen Business School was strong in finance and logistics, while Reims Management School was recognized for its strength in marketing and communication. The combined entity would thus demonstrate more strength and fewer weaknesses. Owing to the availability of a larger pool of resources, more attractive programs can be set up. In particular, corporate clients can be offered better solutions, which would bring in additional revenue to support the school's development. Furthermore, the new entity would have access to the academic partners of each school, thus offering its students a greater variety of overseas study options. In the context of intense competition, merging appears to increase the opportunities without generating additional costs.

\section{Cost savings:}

The merger can help eliminate duplicate costs. For example, each school needs to have a human resources department, subscribe to academic journals and databases, spend on advertising, and maintain information systems. These costs may not be much greater for the combined school, although it would be twice the size. In addition, the reduced funding from local chambers of commerce makes cost savings an urgent priority.

\section{Arguments for reexamining the teaching loads}

The aim of reducing teaching loads was to incentivize faculty members to publish at a time when few of them were actively engaged in research. It also made the schools attractive employers for young promising academics who might have been concerned by the lack of research culture. Overall the strategy has been highly successful. It has boosted research output and ensured better recruitments. Interestingly smaller French schools are now following the same strategy by offering teaching loads as low as 120 hours a year. However, having achieved its goal of increasing research output, the school's leadership considered that they no longer needed to provide teaching relief.

\section{Most likely choice for non-research active staff}

Being assigned to the AQ category presents the advantage of a lower teaching load of 180 hours a year. The requirement in terms of publications is not overwhelming. Some CNRS-ranked management journals are not overly selective. Hence, a target of the equivalent of 3 stars over three years is a tempting one. However, the risk is that these staff might not achieve the designated target. After all, the conditions will not be different from those they already experienced. Accordingly the outcome is likely to be similar. Given the consequences of not meeting their targets, it might seem prudent for them to apply for PQ status, and teach more without the fear of not delivering. As a result, while not actually imposing such a choice, the school may encourage a number of academic staff to increase their teaching load. 


\section{Likely effect on teaching quality}

Forcing faculty to teach more may have adverse consequences on teaching quality. Staff may experience fatigue after teaching long hours, which may affect their enthusiasm and performance in the classroom. It is also likely that some staff will attempt to minimize their workload. Several strategies may be used in this respect:

- Removing difficult parts of the curriculum to minimize teaching effort and requests for consultation

- $\quad$ Using student presentations to limit teaching preparation

- $\quad$ Using multiple choice questions in exams to reduce grading work

- $\quad$ Making excessive use of questions requiring quantitative answers, since they are easier to mark

\section{Unintended consequences of removing the higher weighting for new courses}

Preparing new courses is extremely time-consuming. The higher weight of 1.5 was designed to offset (to some degree) the greater amount of time spent preparing lecture notes and presentation slides, solutions to problems, new assessment tasks and exam questions. Without proper compensation for this significant effort, it is unlikely that academic staff will be eager to teach new courses. As a result, the quality and topicality of the school's programs may eventually suffer. This would particularly affect graduate programs whose appeal lies precisely in their quality and state-of-the-art nature. If that is the case, intake could drop, which would affect the school's finances. 